\title{
Responsividade e ato responsável em sala de aula: uma experiência com alunos de uma comunidade de baixa renda em Maceió, Alagoas
}

\section{Resumo:}

\author{
Antônio Carlos Santos de Lima* \\ Danielly Verçosa Silva*
}

O presente trabalho é uma reflexão oriunda de um contexto de ensino aprendizagem de língua portuguesa com alunos pertencentes a comunidades de baixa renda na cidade de Maceió, Alagoas. A partir do conceito de atitude responsiva ativa (BAKHTIN, 2003), (BAKHTIN/VOLOCHINOV, 2006) e de ato responsável (BAKHTIN, 2010), analisamos a produção de uma aluna em atividade de leitura e produção de textos. A partir dessa análise, concluímos que uma conduta metodológica adequada do professor de língua materna subjacente a uma concepção de língua e leitura dialógica podem transformar o contexto de sala de aula num espaço promotor de desenvolvimento ou aprimoramento da responsividade, configurando-se como um ato responsável.

Palavras-chave: Responsividade; Sala de Aula; Ato Responsável.

\begin{abstract}
This work is a reflection coming from a teaching context learning Portuguese with students from low-income communities in the city of Maceió, Alagoas. From the concept of active responsive attitude (BAKHTIN, 2003), (BAKHTIN/VOLOCHINOV, 2006) and responsible act (BAKHTIN, 2010), we analyzed the production of a student in reading activity and production of texts. From this analysis, we conclude that a proper methodological conduct Teacher underlying native language to a language and dialogic reading design can transform the classroom context a development promoter space or improving responsiveness, configured as a responsible act.
\end{abstract}

Key-words: Responsivity; Classroom; Responsible act.

\section{Introdução}

Os estudos bakhtinianos têm nos levado a refletir sobre diversos fenômenos observados no dia-a-dia do contexto educacional. Uma dessas questões pode estar associada, também, à educação como ato responsável (BAKHTIN, 2010). Nesse contexto de educação como ato responsável, destaca-se o ensino da língua como um importante

\footnotetext{
* Doutorando no Programa de Pós-graduação em Letras e Linguística da Universidade Federal de Alagoas. Professor do Instituo Federal de Alagoas. E-mail: professorantoniolima@ hotmail.com.

* Doutoranda no Programa de Pós-Graduação em Letras e Linguística da Universidade Federal de Alagoas. Professora da rede municipal de Passo de Camaragibe, Alagoas. E-mail: danyvercosa@yahoo.com.br
}

Revista Leitura V.1 no 55 - jan/jun 2015 - Número temático: Estudos em perspectivas dialógicas. Responsividade e ato responsável em sala de aula: uma experiência com alunos de uma comunidade de baixa renda em Maceió, Alagoas. Antônio Carlos Santos de Lima e Danielly Verçosa Silva - p. 9 - 22. 
fator de promoção da responsividade ${ }^{1}$, uma vez que, para Bakhtin (2003, p. 261) "os diversos campos da atividade humana estão ligados ao uso da linguagem". Assim, na perspectiva bakhtiniana, a língua não é um sistema abstrato de normas (BAKHTIN/VOLOCHINOV, 2006), mas um processo de evolução ininterrupto, que se realiza através da interação verbal social dos locutores (BAKHTIN/VOLOCHINOV, 2006, p. 132, grifos dos autores).

A partir dessas ponderações, consideremos que é importante a adoção de uma adequada concepção de linguagem como norte da prática pedagógica, para que, numa atitude responsável, seus reflexos contribuam para "fortalecer o ativismo dos alunos na perspectiva de reconstrução de sentidos (LIMA; SOUTO MAIOR, 2012, p. 399), o que pode torná-los em condições de atuarem efetivamente nos seus respectivos contextos.

Corroborando com a afirmação de Kramer (2013) que, ao citar Bakhtin, afirma que "a educação é apresentada como experiência humana nas suas dimensões epistemológica, ética e estética (p. 29), Verçosa (1999), em sua obra A propósito dos textos didáticos na prática escolar, incita-nos a refletir sobre as problemáticas que permeiam o processo pedagógico, ao mesmo tempo que nos faz vislumbrar práticas que minimizem essas problemáticas. Segundo esse pesquisador, o processo educativo é historicamente determinado por uma imposição de produção/reprodução de um modelo de sociedade que é determinado pela classe dominante. Assim, o contexto educacional pode ser permeado por muitas situações de conflito, em que se apresentam o confronto social, os encontros e os desencontros, as aproximações e as rejeições, e manifestam-se comportamentos de subordinação e resistência (ANDRÉ, 1995). Nesse contexto de diálogo, de confronto e de tensões entre os interlocutores, que se evidencia no espaço escolar, há a necessidade de, nesse espaço, serem promovidas estratégias pedagógicas que regulem o funcionamento discursivo definido na própria relação de interlocução, em função dos modelos já instituídos (RANGEL, 2007). Essas estratégias podem ser adquiridas por uma prática de

\footnotetext{
1 A partir das reflexões de Bakhtin (2003) e Bakhtin/Volochinov (2006), podemos definir responsividade como uma parte de um diálogo que está para a enunciação assim como uma réplica está para a outra parte nesse diálogo. É a oposição ao locutor de uma contra palavra. É uma reação a partir daquilo que se compreende no processo de interação. Orginalmente, Bakhtin (2003) e Bakhtin/Volochinov (2006) denominam de atitude responsiva ativa. Neste texto, atitude responsiva ativa ou responsividade podem ser usadas indistintamente.
}

Revista Leitura V.1 no 55 - jan/jun 2015 - Número temático: Estudos em perspectivas dialógicas. Responsividade e ato responsável em sala de aula: uma experiência com alunos de uma comunidade de baixa renda em Maceió, Alagoas. Antônio Carlos Santos de Lima e Danielly Verçosa Silva - p. 9 - 22. 
ensino de língua que promova, aprimore, desenvolva a responsividade, uma atitude que instrumentaliza os sujeitos para uma eficaz prática social. Assim, esse espaço educacional estaria se configurando com um contexto propício ao ato responsável nos termos bakhtinianos.

É nessa perspectiva que apresentamos a presente reflexão, a partir da análise de práticas pedagógicas oriundas de ações fundamentadas no ato responsável (BAKHTIN, 2010) que podem contribuir para o desenvolvimento e/ou aprimoramento de atitudes responsivas ativas (BAKHTIN, 2003), (BAKHTIN/VOLOCHIVOV, 2006) dos alunos.

Ancorada nos marcos da Linguística Aplicada e utilizando uma abordagem de pesquisa "interpretativista"2 (MOITA LOPES, 1996) de cunho etnográfico (ANDRÉ, 1995; CHIZZOTTI, 1995; LÜDKE \& ANDRÉ, 1986; TRIVINÕS, 1987), bem como princípios metodológicos da pesquisa-ação (THIOLLENT, 1988), procederemos nossa reflexão a partir da análise de aulas de um projeto de pesquisa-ação, intitulado "Comunidades de Maceió", e desenvolvido pelo Grupo de Estudos Ensino e Aprendizagem de Línguas ${ }^{3}$, vinculado à Faculdade de Letras da Universidade Federal de Alagoas.

\section{Contribuições de Bakhtin para o ensino da língua e para a responsividade: uma proposta para o ato responsável}

Não são tão recentes as discussões acerca da concepção de língua como norte para prática pedagógica do professor, tanto o de línguas estrangeiras quanto o da materna. Entretanto, muito pouco se tem logrado dessas discussões.

Atualmente, o campo dos estudos da linguagem tem se valido das contribuições de Bakhtin e de seu círculo para aprimorar prática na sala de aula de línguas, pois suas reflexões têm oferecido uma adequada fundamentação acerca do processo de uso da linguagem. Para Bakhtin/Volochinov (2006) e seu círculo, a enunciação, compreendida como uma réplica do diálogo social, é ideológica, ou seja, nela, através da palavra, se imprime toda uma carga social; ela é um signo linguístico. Nesse sentido "a palavra veicula, de maneira privilegiada, a ideologia; a ideologia é uma superestrutura, as

\footnotetext{
${ }^{2}$ Tipo de pesquisa comumente conhecido como "qualitativa". Preferimos aquela denominação para evitar uma ideia de dicotomia qualitativa versus quantitativa, já que defendemos a posição de que esses tipos de estudos não se excluem, mas, muitas vezes, completam-se.

${ }^{3}$ O Grupo de Estudos e o projeto de pesquisa-ação citados são coordenados pela Profa. Dra. Rita Zozzoli e vice coordenado pela Profa. Dra. Rita Souto Maior, ambas professoras da Faculdade de Letras da Universidade Federal de Alagoas.
}

Revista Leitura V.1 no 55 - jan/jun 2015 - Número temático: Estudos em perspectivas dialógicas. Responsividade e ato responsável em sala de aula: uma experiência com alunos de uma comunidade de baixa renda em Maceió, Alagoas. Antônio Carlos Santos de Lima e Danielly Verçosa Silva - p. 9 - 22. 
transformações sociais da base refletem-se na ideologia e, portanto, na língua que as veicula" (BAKHTIN/VOLOCHINOV, 2006, p. 17). Assim, cada ato enunciativo é composto por várias vozes, ou seja, um discurso é um conjunto de vários outros construídos histórica e socialmente. Na sala de aula, por exemplo, esses discursos precisam ser compreendidos para que, através da expansividade, se estabeleçam os diálogos. Assim, esses discursos, refletem o ato que, de forma responsável, deve contribuir para o equilíbrio das tensões sociais.

Somente a partir do interior de tal ato como minha ação responsável, e não de seu produto abstratamente, pode haver uma saída para a unidade do existir. Somente do interior de minha participação pode ser compreendida a função de cada participante. No lugar do outro, como se estivesse em meu próprio lugar, encontro-me na mesma condição de falta de sentido. Compreender um objeto significa compreender meu dever em relação a ele (a orientação que preciso assumir em relação a ele), compreendê-lo em relação a mim na singularidade do existir-evento: o que pressupõe a minha participação responsável, e não a minha abstração (BAKHTIN, 2010, p. 65-6).

Yaguello (2006), ao nos expor as ideias de Bakhtin/Volochinov (2006), sintetiza a questão da linguagem como forma de atuação para o ato responsável quando afirma que, para esses filósofos da linguagem, se a língua é determinada pela ideologia, a consciência e o pensamento são também condicionados por uma linguagem por ela modelada. A interação pela linguagem se estabelece em inter-relações recíprocas, orientadas, mas sem excluir uma ação resposta (BAKHTIN/VOLOCHINOV, 2006, p.16), o que se configura como uma atitude responsiva ativa. Isso porque cada sujeito utiliza o enunciado para imprimir seu ponto de vista, o que, dialeticamente, também se constitui numa resistência, como afirma Gnerre (1987, p. 3): “as pessoas falam para serem 'ouvidas', às vezes para serem respeitadas e também para exercer uma influência no ambiente em que se realizam os atos linguísticos”. Assim, se o discurso de outrem não me é convincente, adequado, automaticamente eu lhe apresento um contra discurso.

Dessa forma, na perspectiva desse filósofo da linguagem, tanto o sujeito quanto a linguagem são constituídos na relação de um com o outro (sujeito-linguagem e linguagemsujeito), assim como com os outros sujeitos do discurso, com a ideologia, com a história etc. Dessa maneira, observamos que tudo se constitui e se reconstitui em uma grande e infinita cadeia dialógica, por isso que a realidade se apresenta em evolução ininterrupta (BAKHTIN/VOLOCHÍNOV, 2006).

Revista Leitura V.1 no 55 - jan/jun 2015 - Número temático: Estudos em perspectivas dialógicas. Responsividade e ato responsável em sala de aula: uma experiência com alunos de uma comunidade de baixa renda em Maceió, Alagoas. Antônio Carlos Santos de Lima e Danielly Verçosa Silva - p. 9 - 22. 
O fenômeno linguístico, por sua vez, visto por Bakhtin/Volochinov (2006) como fato da língua e não como abstração do real (puramente linguístico), deve ser estudado em relação com seu contexto. Bakhtin (1998, p. 87), assim, afirma a necessidade do estudo do contexto apresentada através de uma metáfora: "A atmosfera social do discurso que envolve o objeto faz brilhar as facetas de sua imagem". Desse modo, se não observarmos o social, o contexto no qual o discurso é constituído, fica difícil entendermos o fenômeno, dar os possíveis significados ao objeto analisado.

O termo contexto, comumente utilizado em pesquisas interpretativistas, possibilita muitas significações, por isso apontaremos a concepção com a qual trabalhamos. Consideramos que não é fácil definir o termo em questão por seu significado amplo, porém concordamos com a noção de Bakhtin (2010, p. 112) que a apresenta como "um certo horizonte social" definido e estabelecido que determina a criação ideológica. Dessa forma, o contexto tem uma natureza social de grande relevância para o entendimento do fenômeno estudado, pois, segundo Bakhtin (2003, p. 294), a palavra é expressiva, mas essa expressão não é inerente a ela, mas ao contato dela com o contexto que a circunda. Assim, observamos que o significado do fenômeno linguístico, no caso de nosso estudo, constituise dentro de um contexto que o influencia.

Assim, todo discurso, objeto de principal reflexão dos estudos linguísticos, tem uma orientação dialógica, sendo ela de diversos graus e de diversas maneiras, conforme Bakhtin (1998). Dessa forma, os interlocutores do discurso interagem de forma ativa, formando-se como sujeitos na língua e através dela e isso acontece de várias formas.

Para Bakhtin (2003), o discurso sempre se apresentará em forma de enunciados, pertencentes a seus interlocutores, essa é, então, a unidade real da comunicação discursiva. Esses enunciados possuem limites e características composicionais, não se apresentando como unidade convencional, mas real na cadeia comunicativa. Assim, ao considerar o outro com o qual o sujeito se envolve no discurso como ouvinte/falante ou leitor/escritor, esse posicionamento apresenta a possibilidade de alternância entre os interlocutores e tal alternância é quem define o limite do enunciado.

O discurso é composto por uma possível resposta e determinado, de certa forma, por ela, pois os interlocutores organizam todo o discurso a partir dessa possibilidade de resposta e essa resposta pode reforçá-lo, enriquecê-lo, contradizê-lo, enfim, defini-lo de alguma maneira (BAKHTIN, 1998). Segundo Bakhtin (1998, 2003) e Bakhtin/Volochinov

Revista Leitura V.1 no 55 - jan/jun 2015 - Número temático: Estudos em perspectivas dialógicas. Responsividade e ato responsável em sala de aula: uma experiência com alunos de uma comunidade de baixa renda em Maceió, Alagoas. Antônio Carlos Santos de Lima e Danielly Verçosa Silva - p. 9 - 22. 
(2006), podemos denominar essa resposta que compõe o discurso como "atitude responsiva ativa", que, de acordo com o pensador, se realiza quando o sujeito,

ao perceber e compreender o significado (linguístico) do discurso, ocupa simultaneamente em relação a ele uma ativa posição responsiva: concorda ou discorda dele (total ou parcialmente), completa-o, aplica-o, prepara-se para usá-lo, etc. (BAKHTIN, 2003, p. 271).

$\mathrm{O}$ autor ainda defende que essa responsividade nem sempre se realiza linguisticamente, podendo se manifestar através de outros elementos, como gestos ou até mesmo o silêncio. Com isso, consideramos que, na sala de aula, a atitude ativa seria, principalmente, uma postura responsiva ao que é dito ou apresentado, uma posição diferente da "dublagem", da reprodução, algo tão presente nas atuais práticas de alunos no que se refere à leitura e à produção de textos.

Para explicar a noção de atitude responsiva ativa, ou de responsividade, Bakhtin recorre a um outro conceito, o de "compreensão responsiva ativa" (BAKHTIN, 2003), pois, para ele, o sujeito se posiciona ativamente em relação a determinado discurso após compreendê-lo e essa compreensão é sempre "ativamente responsiva". A respeito disso, o autor afirma que

Toda compreensão da fala viva, do enunciado vivo é de natureza ativamente responsiva (embora o grau desse ativismo seja bastante diverso); toda compreensão é prenhe de resposta, e nessa ou naquela forma a gera obrigatoriamente: o ouvinte se torna falante. A compreensão passiva do significado do discurso ouvido é apenas um momento abstrato da compreensão ativamente responsiva real e plena (BAKHTIN, 2003, p. 271).

Dessa forma, percebemos que o grau de ativismo da compreensão, assim como o da atitude é oscilante, podendo variar de acordo com o contexto situacional. Assim, um mesmo sujeito pode apresentar esse ativismo em maior ou menor grau, mas sempre o apresentará, porque toda compreensão é ativamente responsiva e uma fase inicial para a resposta (atitude responsiva ativa) que cedo ou tarde surgirá (BAKHTIN, 2003, p. 272). Bakhtin (1998, p. 90) defende, ainda, que a compreensão e a resposta estão fundidas e uma não existe sem a outra, pois a compreensão só amadurece na resposta.

$\mathrm{Na}$ constituição do discurso, ainda, o falante já aguarda a compreensão ativa do outro e essa possibilidade de resposta influencia na constituição do enunciado do falante. Dessa forma, o "endereçamento", o destinatário é um dos traços principais do enunciado. Esse destinatário pode ser o outro participante direto do diálogo, pode ser uma coletividade, pode ser um outro totalmente indefinido, etc. Ao considerar destinatário, 
respondo antecipadamente a ele, além de determinar o gênero discursivo a ser utilizado (BAKHTIN, 2003, p. 301, 302).

Por meio dessa "atitude ativa" (BAKHTIN, 2003), o sujeito nunca é passivo diante do discurso do outro, ele não recebe passivamente nada do que lhe é apresentado. $\mathrm{O}$ sujeito responderá e mostrará sua relativa autonomia diante dessa imagem que está sendo imposta, vendida, constituindo-se, dessa forma, diferentemente uns dos outros, embora a ideia de igual, de estereótipos ${ }^{4}$, possa, às vezes, parecer real.

Através dessa relação e do que Bakhtin denomina "alteridade" (BAKHTIN, 2003), notamos que o eu se constitui a partir do que apresenta como diferente do outro e vice-versa. Então, a visão de diferença do outro em relação ao eu constitui o eu assim como o próprio outro. A respeito dessa questão da diferença entre o eu e o outro, Bakhtin (2003, p. 21) afirma que

Quando nos olhamos, dois diferentes mundos se refletem na pupila dos nossos olhos. Assumindo a devida posição, é possível reduzir ao mínimo essa diferença de horizontes, mas para eliminá-la inteiramente urge fundir-se em um todo único e formar uma só pessoa.

Percebemos, com o exemplo utilizado pelo autor, que a diferença "de horizontes" mencionada é essencial para delimitar quem é um e quem é outro, sendo essa diferença constitutiva do próprio eu e do outro, senão não se constituiriam como duas pessoas e sim como uma só. Além disso, observamos que ela apresenta grau variável.

Para explicitar o caráter constitutivo da diferença, Bakhtin (2003, p. 22-23) explica, ainda que

O excedente de minha vida em relação ao outro indivíduo condiciona certa esfera do meu ativismo exclusivo, isto é, um conjunto daquelas ações internas ou externas que só eu posso praticar em relação ao outro, a quem elas são inacessíveis no lugar em que ele ocupa fora de mim; tais ações completam o outro justamente naqueles elementos em que ele não pode completar-se.

O filósofo, ainda, conclui que essas ações podem ser variáveis, pois são diversos os momentos e situações que o eu e o outro se encontram. Notamos, com isso, que a “compreensão responsiva ativa" (BAKHTIN, 2003) em relação ao outro possibilita "atitudes responsivas ativas" (BAKHTIN, 2003) para com esse outro, ou seja, discursos, maneiras de comportar-se, recusa de diálogo etc. E essas ações que, por sua vez, apenas podem ser exercidas pelo eu, de acordo com sua compreensão ativa e com sua visão,

\footnotetext{
${ }^{4}$ Consideramos estereótipos como produto de uma homogeneização imaginária de traços identificados como fixos e que devem ser reproduzidos (BHABHA, 1998, p. 117-119).
}

Revista Leitura V.1 no 55 - jan/jun 2015 - Número temático: Estudos em perspectivas dialógicas. Responsividade e ato responsável em sala de aula: uma experiência com alunos de uma comunidade de baixa renda em Maceió, Alagoas. Antônio Carlos Santos de Lima e Danielly Verçosa Silva - p. 9 - 22. 
completa o outro, pois influencia suas atitudes e sua própria constituição por meio da ação, da visão do outro.

Esse sujeito, dessa forma, não se confunde com o outro nem com a sociedade, apesar de social, mas é um ser real, existe como sujeito, um sujeito "uno" (BAKHTIN, 2010) no outro, pois eles estão sempre em um diálogo constitutivo, dessa forma, não existe eu sem o outro e vice-versa.

Bakhtin, ao nosso ver, utiliza o termo "uno" para deixar claro a existência de um ser que não se confunde com o social nem nele se dilui, apesar de não poder existir independentemente dessa exterioridade. Acrescentemos que esse sujeito uno não é um ser psíquico abstrato, mas um ser-acontecimento-real, portanto, inserido na história.

\section{$O$ contexto da pesquisa}

O projeto "Comunidades de Maceió" foi uma ação que ofereceu cursos de Línguas Portuguesa e Inglesa a comunidades dessa cidade. As turmas formavam-se a partir do interesse dos alunos no curso, pois todas os sujeitos que manifestavam interesse em participar dos cursos poderiam ingressar sem, necessariamente, serem submetidos a um processo seletivo. As únicas exigências apresentadas para a participação como discente nos cursos eram que os interessados deveriam ter no mínimo 15 anos de idade, serem alfabetizados e pertencerem a comunidades consideradas de baixa renda.

As aulas foram realizadas nas dependências da Casa de Cultura Britânica da Universidade Federal de Alagoas semanalmente, durante duas horas e quinze minutos, e ministradas por professores-pesquisadores do grupo de pesquisa já citado, que atuavam conjuntamente tanto na sala de aula quanto fora dela.

O curso possuía um programa base que norteava o trabalho executado em sala, mas sempre era flexível, pois se ajustava às condições do trabalho com a turma. Dessa forma, os materiais e os conteúdos trabalhados nessa sala eram elaborados a partir das necessidades detectadas na turma em questão, através da discussão dessas necessidades entre os professores-pesquisadores. Assim, os temas apresentados nos textos eram sugeridos pelos próprios alunos, havendo, ainda, uma adequação desses temas ao contexto no qual eram inseridos os sujeitos.

Analisaremos alguns eventos a partir da responsividade de uma aluna participante do curso de Língua Portuguesa. A aluna em questão pertencia à comunidade da Vila de 
Pescadores do bairro de Jaraguá. Essa comunidade está localizada ao lado do Porto de Jaraguá, às margens da orla desse bairro histórico da cidade de Maceió-AL. É composta principalmente de pescadores, de marisqueiras e de seus familiares, embora pessoas com outras ocupações também morem no local. Não podemos precisar até que ponto elas possuem parentesco com os profissionais que vivem da pesca. Com estrutura bastante simples, a referida comunidade também é conhecida como Favela de Jaraguá em grande parte da cidade. Além disso, ela é constantemente considerada pela imprensa como lugar ${ }^{5}$ violento, com envolvimento com drogas.

\section{O sujeito e a responsividade: uma cena em sala de aula}

Apresentaremos dados de $\mathrm{Ana}^{6}$, uma aluna do curso de Leitura e Produção de Textos em Língua Portuguesa, que encontrava na faixa etária de 25 a 30 anos e cursava o $1^{\circ}$ ano do Ensino Médio.

$\mathrm{Na}$ sexta aula do segundo semestre do curso, após discussão acerca de inadequações encontradas nos textos dos alunos, Ana lança uma proposta de atividade para a próxima aula, uma vez que essa atitude era permitida pela metodologia do curso. Segundo Ana, "cada um deveria escrever um texto, ler em sala e os outros diriam o que achou". A proposta foi aceita pelos outros sujeitos envolvidos no processo de ensinoaprendizagem. Aceita a proposta, a professora-pesquisadora conduziu a atividade, solicitando a produção textual aos alunos. Observemos que essa postura de Ana sinaliza para uma dinâmica de sala de aula diferente das habitualmente identificadas, o que já se apresenta como uma marca de responsividade, pois sua proposta se diferencia do que comumente é visto em sala de aula, mas "o sujeito da compreensão não pode excluir a possibilidade de mudança e até de renúncia aos seus pontos de vista e posições já prontos. No ato da compreensão desenvolve-se uma luta cujo resultado é a mudança mútua e o enriquecimento" (BAKHTIN, 2003, p. 378).

O fato de Ana ter feito a proposta de atividade e esse fato não ser comumente verificado é um fator de grande relevância para análise em questão, porque também revela que o ato responsável em sala de aula deve instaurar o diálogo, permitindo a coexistência

\footnotetext{
5 Aqui não fazemos distinção entre "espaço" e "lugar". Conforme alguns autores, como De Certeau (2008), consideramos, dessa maneira, o termo numa acepção mais ampla. A palavra lugar aparece constantemente no estudo para se referir à comunidade, aquele local específico.

${ }^{6}$ Nome fictício para preservar a identidade da participante.
}

Revista Leitura V.1 no 55 - jan/jun 2015 - Número temático: Estudos em perspectivas dialógicas. Responsividade e ato responsável em sala de aula: uma experiência com alunos de uma comunidade de baixa renda em Maceió, Alagoas. Antônio Carlos Santos de Lima e Danielly Verçosa Silva - p. 9 - 22. 
de forças, ora convergentes ora divergentes, mas que necessárias para essa interação dialógica. Entretanto, não basta apenas proporcionar esse espaço dialógico, mas proporcionar espaços para a dialogicidade e estimular a responsividade, pois "o sujeito da compreensão enfoca a obra com sua visão de mundo já formada, de seu ponto de vista, de suas posições" (BAKHTIN, 2003, p.378).

Apresentaremos a transcrição ${ }^{7}$ do texto que Ana escreveu em casa, a partir da leitura oral feita por essa aluna em sala. Destacamos um trecho do texto para posteriormente discuti-lo.

Preconceito sexual / nós seres humanos / temos a mania de julgar as pessoas / sem saber / quem realmente são. Achamos que temos o direito de julgar / de criticar / mas na verdade não temos. Há vários tipos de preconceito / o racial / o social / o homossexual etc. Uma pessoa que é / homossexual o caráter dela não está na opção que ela escolheu / pois ela pode ser uma pessoa honesta e decente. Nós temos que respeitar as pessoas / independente do que elas são / ou seja / em primeiro lugar está o respeito. O brasileiro é muito preconceituoso / mas aos poucos isso está mudando / ainda falta muito / mas a gente chega lá. Várias pessoas / o homem tem que ser mulherengo / ter a fama de pegador / tem que ser machão / homem não pode chorar / Será que isso é ser homem de verdade? A minha opinião ser homem é / ter caráter / digno / e respeitar outros / isso sim é ser homem / pois se um homem chora dizem logo / esse cara é veado / ser educado, gentil / ah esse cara deve ser bicha. Minha gente está tudo errado na maneira de pensar / na mentalidade (XXX). As famílias estão se destruindo / desmoronando / e os filhos não respeitam seus pais e viceversa / pois os mesmos / estão deixando de ensinar os verdadeiros valores aos seus filhos / Hoje o que os pais ensinam / é pegar mulher pro filho / é ele ser famoso / o rapaz quando arruma uma namorada / mal conhece e já leva pra dormir em casa / e tantas outras tolices / mas não ensina a ele a ser um homem de bem, de caráter, decente.

\section{Quadro 1: Texto transcrito de Ana}

Analisando esse texto produzido por Ana podemos asseverar a ideia de que todo discurso faz parte de uma cadeia dialógica ininterrupta e se constitui como uma resposta a um outro discurso. Notamos que, no texto, não só a questão da sexualidade, mas a própria noção de homem é revisitada pela aluna. Ela traz características culturalmente construídas

\footnotetext{
7 Transcrição a partir de uma adaptação de Marcuschi (1986, p.12). No texto apresentado, utilizamos especificamente: / = pausa por hesitação (as pausas sintáticas são apresentadas segundo os sinais de pontuação da Gramática Normativa), $(\mathrm{XXX})$ = incompreensão de palavras ou segmentos.
}

Revista Leitura V.1 no 55 - jan/jun 2015 - Número temático: Estudos em perspectivas dialógicas. Responsividade e ato responsável em sala de aula: uma experiência com alunos de uma comunidade de baixa renda em Maceió, Alagoas. Antônio Carlos Santos de Lima e Danielly Verçosa Silva - p. 9 - 22. 
do que é ser homem no trecho do texto destacado por nós, conforme apresentamos no quadro comparativo abaixo:

\begin{tabular}{|l|l|l|}
\hline $\begin{array}{l}\text { Homem, segundo à } \\
\text { sociedade: }\end{array}$ & Homem de verdade: & $\begin{array}{l}\text { Homem de verdade, mas } \\
\text { criticado pela sociedade: }\end{array}$ \\
\hline - mulherengo; & • caráter; & pode chorar (veado); \\
- pegador; & - digno; & educado (bicha); \\
- machão; & - respeitador. & \\
\hline não chora. & & \\
\hline
\end{tabular}

Quadro 2: Visões acerca do homem

Nessa sistematização, podemos perceber que, segundo Ana, a noção de homem é historicamente produzida numa sociedade machista, na qual o sujeito se define como tal a partir de uma posição diferencial do outro e que esse diferencial funciona como elemento na constituição do sujeito. No caso, o que define um (falso) homem de um homem de verdade é a presença/ausência de características, elementos que se contrastam: mulherengo, pegador, machão versus digno, respeitador e com caráter; não chora versus chora; machão (grosso) versus educado, gentil. Dessa maneira, é "x" o que não é " $y$ " e vice-versa.

Notamos, com a apresentação das características do homem e a discussão sobre elas, que Ana discute a questão de gênero de um modo geral, não só o gênero mulher. Dessa maneira, a aluna está produzindo criticamente, pois é acentuado seu posicionamento, sua crítica à visão social a respeito do que é ser homem. Para isso, Ana faz uso de argumentos a fim de que o leitor aceite sua opinião, como, por exemplo, a de que a destruição da estrutura familiar (algo observado e que tem causado grande preocupação atualmente) é ocasionada pelo desrespeito às pessoas, pela falta do ensino dos "verdadeiros" valores aos filhos.

Assim, através de toda a discussão trazida por Ana, constatamos um elevado grau da atitude responsiva ativa da aluna, o que apresenta a aluna como uma leitora e produtora de textos, pois ela se posiciona contra o que reconhece como "errado", não só o que a "toca" (a questão do gênero mulher), mas, de um modo geral, ela discute os papéis na

Revista Leitura V.1 no 55 - jan/jun 2015 - Número temático: Estudos em perspectivas dialógicas. Responsividade e ato responsável em sala de aula: uma experiência com alunos de uma comunidade de baixa renda em Maceió, Alagoas. Antônio Carlos Santos de Lima e Danielly Verçosa Silva - p. 9 - 22. 
sociedade e faz questão de expor isso em seu discurso como um recurso argumentativo para obter a adesão de outras pessoas.

Observamos que todo o discurso de Ana, portanto, é uma marca de responsividade a pelo menos dois discursos: a) o da/o professora/curso que pedia aos alunos uma posição ativa como leitor e produtor de textos, com uma orientação de que a melhoria na vida do cidadão dependia desse posicionamento; b) aos discursos que dos quais Ana possivelmente participava com a temática abordada, em outros contextos, que provocou essa ação responsiva.

Com essa atitude ativa de Ana, percebemos uma postura crítica, na qual a aluna se posiciona ativamente a respeito das questões tratadas, pois embora a sociedade considere deslegitimado o gênero em questão, Ana tenta no decorrer do processo legitimá-lo, mesmo contra uma cultura tradicional e padronizadora de gêneros.

Esse evento de sala de aula pode ser revelador de uma importante constatação: a de que esse espaço, se pautado na proposta do ato responsável, pode ser um lugar transformador de práticas sociais que tem mantido determinados sujeitos em posição de submissão cuja reponsividade fica restrita a um contexto mais imediato e não mais amplo. Entretanto,

As comunidades de falantes não vivem isoladas umas das outras. Pelo contrário, estão em constantes situações de intercâmbio, o que significa dizer que as normas particulares de cada comunidade transitam também para outras, em um movimento dinâmico contínuo de vai-vém (ANTUNES, 2009, p. 28).

Assim, as possibilidades de leitura suscitadas na sala de aula podem ampliar essa interação entre os sujeitos de horizontes sociais diversos, assegurando-lhes o direito de transitarem nas mais variadas esferas sociais. É necessário, portanto, suscitar essa responsividade em sala de aula, pois a educação é uma resposta responsável, como afirma Kramer (2013).

Portanto, é necessário que o professor possibilite o acesso à leitura de diversos gêneros textuais em sala de aula, pois assim, ampliam-se os contatos com diferentes variedades linguísticas e permite ao aluno o desenvolver uma compreensão ativa.

\section{Considerações Finais}

Revista Leitura V.1 no 55 - jan/jun 2015 - Número temático: Estudos em perspectivas dialógicas. Responsividade e ato responsável em sala de aula: uma experiência com alunos de uma comunidade de baixa renda em Maceió, Alagoas. Antônio Carlos Santos de Lima e Danielly Verçosa Silva - p. 9 - 22. 
O presente texto pretendeu apresentar a perspectiva bakhtiniana de responsividade e ato responsável e observar algumas questões trazidas pelo autor na prática escolar, a partir de uma análise sobre uma situação de sala de aula que envolve o discurso de uma aluna participante de um curso de Leitura e Produção de Textos em Língua Portuguesa. Refletimos, dessa forma, sobre o caráter dialógico e o grau de responsividade ativa presentes na prática discursiva descrita de Ana na aula, o que também a constituem como leitora e produtora de textos, cidadã ativa no mundo.

Percebemos, ainda, no texto de Ana, argumentos que defendem, sobretudo, o respeito a diferenças, uma atitude ativa e dialógica em relação a discursos que tentam homogeneizar os sujeitos, transformando-o em aparentemente iguais, desconsiderando as diferenças necessárias existentes entre o eu e o outro, também defendidas por Bakhtin (2003).

Consideramos que a aluna observada, com seu posicionamento, também é um exemplo de possibilidade de atitudes cada vez mais ativas no processo de ensinoaprendizagem, em resposta a certas instâncias de poder que defendem a formação de sujeitos "iguais", formados, inclusive, através da "aprendizagem" por meio da dublagem para que não venham questionar o sistema em que se encontram.

Defendemos, no entanto, que, mesmo no ensino formal, podemos incentivar essa diferença, pois a aprendizagem só acontece quando o sujeito burla esse sistema da dublagem, mesmo teoricamente fazendo parte dele, o que é a tentativa do nosso grupo de estudos ao desenvolver projetos que visam formar leitores e produtores de textos. Esse achado se coaduna com as reflexões feitas por Zozzoli (2002) de que não é comum se verificar uma atitude responsiva ativa no contexto escolar, mas a responsividade se evidencia "quando é efetuado um trabalho que favorece uma resposta ativa do aluno, presente tanto em momentos de compreensão como de produção de textos" (ZOZZOLI, 2002, p. 17).

\section{Referências}

ANDRÉ, M. Etnografia da prática escolar. Campinas: Papirus, 1995. ANTUNES, I. Texto, língua e ensino: outra escola possível. São Paulo: Parábola, 2009.

BAKHTIN, M. O discurso na poesia e o discurso no romance. In: Questões de literatura e de estética. São Paulo, UNESP, 1998.

Revista Leitura V.1 no 55 - jan/jun 2015 - Número temático: Estudos em perspectivas dialógicas. Responsividade e ato responsável em sala de aula: uma experiência com alunos de uma comunidade de baixa renda em Maceió, Alagoas. Antônio Carlos Santos de Lima e Danielly Verçosa Silva - p. 9 - 22. 
BAKHTIN, M. Estética da criação verbal. São Paulo: Martins Fontes, 2003.

BAKHTIN, M. (VOLOCHINOV, V.N.). Marxismo e filosofia da linguagem. 12. ed.

São Paulo: Hucitec, 2006.

BAKHTIN, M. Para uma filosofia do ato responsável. 2.ed. São Paulo: Pedro \& João Editores, 2010.

GNERRE, M. Linguagem, escrita e poder. São Paulo: Martins Fontes, 1987.

KRAMER, S. A educação como resposta responsável: apontamentos sobre o outro como prioridade. In: FREITAS, M. T. de A. Educação, arte e vida em Bakhtin. Belo Horizonte: Autêntica Editora, 2013.

LIMA, A. C. S. de.; SOUTO MAIOR, R. de C. Responsividade e discursos envolventes: observando o ensino e aprendizagem de Língua Portuguesa. In: Eutomia (Recife), v. 2, p.394-413, 2012.

LÜDKE, M.; ANDRÉ, M. A pesquisa em educação: abordagens qualitativas. São Paulo, EPU, 1986.

MARSCUSCHI, L. A. Análise da Conversação. São Paulo: Ática, 1986.

MOITA LOPES, L. P. da. Oficina de linguística aplicada. Campinas: Mercado de Letras, 1996.

RANGEL, J. N. M. Leitura na escola: espaço para gostar de ler. 2. ed. Porto Alegre: Editora Medição, 200.

THIOLLENT, M. Metodologia da pesquisa-ação. São Paulo: Cortez e Autores Associados, 1988.

TRIVIÑOS, A. Introdução à pesquisa em ciências sociais. São Paulo: Atlas, 1987.

VERÇOSA, E. de G. A propósito dos textos didáticos na prática escolar: uma abordagem sociopolítica da ação docente. Maceió: Edições Catavento, 1999.

YAGUELLO, M. Marxismo e filosofia da linguagem. In: BAKHTIN, $M$. (VOLOCHINOV, V.N.). Marxismo e filosofia da linguagem. 12. ed. São Paulo: Hucitec, 2006.

ZOZZOLI, R. Compreensão e produção responsivas ativas: indícios nas produções dos alunos. Ler e produzir: discurso, texto e formação do sujeito leitor/produtor. Rita Maria Diniz Zozzoli (org.). Maceió: EDUFAL, 2002.

Revista Leitura V.1 no 55 - jan/jun 2015 - Número temático: Estudos em perspectivas dialógicas. Responsividade e ato responsável em sala de aula: uma experiência com alunos de uma comunidade de baixa renda em Maceió, Alagoas. Antônio Carlos Santos de Lima e Danielly Verçosa Silva - p. 9 - 22. 